\title{
Research on the Perception of Historical District of Eight Great Passes in Qingdao Based on Online Travel Notes
}

\author{
Lang Xiaoxia ${ }^{1,}{ }^{*}$, Cheng Shiya ${ }^{2}$, Wei Guanyu ${ }^{3}$ \\ ${ }^{1}$ Department of environmental design, Qingdao University of Technology, Qingdao China \\ ${ }^{2}$ Department of environmental design, Qingdao University of Technology, Qingdao China \\ ${ }^{3}$ Department of environmental design, Qingdao University of Technology, Qingdao China
}

\begin{abstract}
In recent years, the protection mode of historical blocks has changed from simple material protection to comprehensive protection integrating various factors, and more and more attention has been paid to the role of human perception. How to pay attention to the practical experience of consumers while protecting has become the main problem. This paper studies the tourists' perception of historical district of Eight Great Passes in Qingdao by using the method of network text analysis, and carries out word frequency analysis, semantic network analysis and emotional analysis on the online travel notes by Rost CM6, so as to comprehend the current situation of tourists' perception of different dimensions of Eight Great Passes historical and Cultural District in Qingdao, and find out the problems in its development as well as put forward the sustainable development strategies
\end{abstract}

\section{Introduction}

According to the $43^{\text {rd }}$ China Internet Development Statistics Report released by China Internet Network Information Center (CNNIC), as of December 2018, the number of Internet users reached 829 million, and the Internet penetration rate was $59.6 \%$, close to $60 \%$. The characteristics of sharing and opening of the Internet not only promote the dissemination and diffusion of tourism information, but also provide a platform for tourists to query and share tourism information and experience.

The tourist perception is a psychological process in which people obtain information about tourist objects and environmental conditions through sensory organs. It can be regarded as an information acquisition in space, tourist object and emotional dimension during traveling, and can also reflect the construction and development status of tourism spots, which is helpful to find and solve problems. Therefore, in recent years, tourist perception has become a hot spot in tourism research. The existing research on tourists' perception mostly adopts questionnaire survey, through which, though we can get the first-hand data, the data obtained from a single survey has narrow time coverage. On the other hand, due to the low degree of cooperation of some tourists, the authenticity of the data may be reduced. With the advent of the era of big data, online travel notes about tour sites and their own feelings share the characteristics of openness and authenticity, which can make up for the shortcomings of traditional questionnaire survey ${ }^{1}$.

Serving as a city recreation space, the tourism function of historical and cultural blocks is becoming increasingly prominent. How to realize the rational development of tourism in historical and cultural blocks from tourists' perception has become an important part in urban tourism construction, and it has also attracted the attention of academic circles. The existing research mainly focuses on the objective space and environment of historical and cultural blocks, while the research on the users, tourists, is relatively weak. This paper will, from the perspective of tourists, analyze frequency of travel notes to study historical district of Eight Great Passes.

\section{Research Design}

\subsection{Research Object}

The name of Eight Great Passes comes from the fact that its main roads are named after the eight famous passes in China. With an area of 70 hectares, the Eight Great Passe is one of the famous scenic convalescent areas in China. Besides, as a representative of the old buildings and European style buildings, it has become an indispensable scenery along the southern coastline of Qingdao. It is also one of the first batch of famous historical and cultural streets in China and one of the main scenic spots in Qingdao.

\subsection{Source and Processing of Data}

In this paper, all samples of travel notes are selected from Ctrip and Qunar, the leading comprehensive travel service platforms in China with a large number of network views and tourism reviews, which are in great

"Corresponding author: ${ }^{148794135 @ q q} . c o m$ 
research and reference value.

With the key word of "Qingdao Eight Great Passe", a total of 1760 travel notes were searched on Ctrip. To ensure a timeliness and universality, the author selects the travel notes from June 2018 to June 2019 on Ctrip, and selects the comments with "Qingdao Eight Great Passe" as the key words from January 2018 to August 2019 on Qunar. In general, a total of 87 travel notes and 557 comments are selected as the research object on this paper.

All collected travel notes and comments are converted into TXT text format, and jumbled words such as "Da" and "De" that have no obvious reference or extensive meaning, travel notes without information and have nothing to do with historical and cultural blocks are removed. At the same time, the meaningless contents such as artificial emoticons, link websites and information in Baidu are deleted to ensure the consistency of the text, after which, about 85364 words of effective text information were sorted out. Finally, the TXT text is imported into the Rost CM6 software for further analysis.

\subsection{Analysis Method}

In this paper, the Rost Content Mining is used to analyze the word frequency, semantic network and emotional attitude of travel notes. Before analysis, a dictionary is defined, including the names of main tourist attractions, place names, names of people, snacks, activities, emotions, etc ${ }^{2}$. The preliminary result is obtained after word segmentation and word frequency statistics. According to the frequency of high-frequency words and other words appearing at the same time, semantic network analysis is carried out to get the semantic network graph, and then the key words about tourists' perception to Eight Great Passe can be got. According to the emotional function analysis, the proportion of positive, neutral and negative attitudes is obtained.

\section{Research Results}

\subsection{Analysis of High-Frequency Words}

After data processing mention above, the top 50 high-frequency words in travel notes and tourist comments are selected from high to low according to the frequency of occurrence, as shown in Table 1. In generally, the parts of speech of high frequency words are mainly nouns, adjectives and verbs ${ }^{3}$. Nouns mainly refer to the local tourist destinations, scenic spots, streets, buildings, snacks, transportation, blocks and accommodation in Qingdao; adjectives are tourists' subjective evaluation of food and snacks, natural environment and historical and cultural atmosphere, scenic spots and objective conditions, and tourists' own overall sightseeing process; verbs show tourists' thoughts, behaviors and perceptions in the process of tourism.

Table 1 Top 50 High-Frequency Words (Table Source: compiled by Rost CM6)

\begin{tabular}{|c|c|c|c|c|c|c|c|}
\hline Rank & Word & Frequency & $\begin{array}{l}\text { Part of } \\
\text { Speech }\end{array}$ & Rank & Word & Frequency & $\begin{array}{l}\text { Part of } \\
\text { Speech }\end{array}$ \\
\hline 1 & Eight Great Passe & 871 & noun & 26 & Ten & 73 & noun \\
\hline 2 & Qingdao & 423 & noun & 27 & $\begin{array}{l}\text { World Architecture } \\
\text { Expo }\end{array}$ & 67 & adjective \\
\hline 3 & Architecture & 397 & noun & 28 & history & 61 & noun \\
\hline 4 & Huashilou & 290 & noun & 29 & Blue sea and clear sky & 60 & adjective \\
\hline 5 & Princess House & 255 & noun & 30 & visit & 60 & verb \\
\hline 6 & style & 168 & noun & 31 & Environmental Science & 57 & noun \\
\hline 7 & place & 162 & noun & 32 & beautiful & 55 & adjective \\
\hline 8 & famous & 160 & adjective & 33 & tourist & 53 & noun \\
\hline 9 & villa & 153 & noun & 34 & European style & 52 & adjective \\
\hline 10 & seaside & 133 & noun & 35 & $\begin{array}{l}\text { Red tiles and green } \\
\text { trees }\end{array}$ & 51 & adjective \\
\hline 11 & scenic spot & 126 & noun & 36 & summer & 50 & noun \\
\hline 12 & scenery & 117 & noun & 37 & locate & 47 & verb \\
\hline 13 & road & 108 & noun & 38 & worth & 44 & verb \\
\hline 14 & $\begin{array}{l}\text { No.2 Bathing } \\
\text { Beach }\end{array}$ & 106 & noun & 39 & various & 43 & adjective \\
\hline 15 & name & 104 & verb & 40 & sandy beach & 40 & noun \\
\hline 16 & admission ticket & 98 & noun & 41 & Juyongguan Road & 40 & noun \\
\hline 17 & Butterfly House & 97 & noun & 42 & Spanish style pavilion & 40 & noun \\
\hline 18 & photograph & 90 & verb & 43 & tree & 40 & noun \\
\hline 19 & Denmark & 85 & noun & 44 & the Great Wall & 39 & noun \\
\hline 20 & characteristic & 84 & noun & 45 & Zhengyangguan Road & 38 & noun \\
\hline 21 & Wedding photos & 84 & noun & 46 & take a walk & 38 & verb \\
\hline 22 & pass & 81 & noun & 47 & autumn & 37 & noun \\
\hline 23 & time & 80 & noun & 48 & Shanhaiguan Road & 37 & noun \\
\hline 24 & street & 75 & noun & 49 & stroll & 35 & verb \\
\hline 25 & fit & 75 & verb & 50 & film & 33 & noun \\
\hline
\end{tabular}


As can be seen from table 1, the high-frequency words related to architecture occupy the largest proportion in the top 50. Among them, "Qingdao" ranked the first and Eight Great Passes, the second, were the words searched when collecting travel notes. Therefore, "architecture" ranked third was the most important core high-frequency word with a frequency of 397 times, indicating that this is the most profound and relevant part of people's perception.

The word "World Architecture" ranked 27th, reflecting people's strong perception of the positioning of "World Architecture Expo" of Eight Great Passe. In addition, Huashilou (290 times), Princess House (255 times), Butterfly House (97 times) and Spanish style Pavillion (40 times) have also received great attention. By the way, the tourists have the preference for Huashilou, for it is very close to the second bathing beach. The words "style", "Danish style" and "European style" appeared 168 times, 85 times and 52 times respectively, which shows that the architectural style of Eight Great Passe can leave a deep impression for people. "Red tiles and green trees" appeared 51 times with a rank of 34, and the word "tree" appeared 40 times with a rank of 43, reflecting the diversity of trees in Eight Great Passe. Meanwhile, the blue sea, clear sky, red tiles and green trees can all be clearly displayed in Eight Great Pass.

The words, related to daily leisure activities like "scenic spot", "scenic spot" "park", "seaside, visit", "walk" and "history" are also in high frequency, which reflects the main cognition and feeling of tourists to Eight Great Passe in Qingdao. The words "take a walk", "stroll" appear 38 times and 35 times respectively, proving that walking is the most important way of sightseeing in the block and one of people's leisure activities. The word "visit" has appeared 60 times with a rank of 30, indicating that visiting buildings is also one of people's leisure activities owing to the characteristic architectural style of the block. Besides, people have a higher perception of the seaside leisure activities, the words "the second bathing beach" and "beach" appeared 106 times and 40 times respectively.

In addition, the word " photograph " has a high degree of tourists' perception with 90 times, because almost everyone has to do it when they go to here. Some even invite a professional team to take photos for them, which proves the beautiful scenery and unique architectural landscape of Eight Great Passes.

\subsection{Semantic Network Analysis}

The co-occurrence semantic network diagram is generated under the social network and semantic network analysis function of Rost Content Mining 6, which helps to show the overall element relations visually, and provide ideas for further analysis ${ }^{4}$.

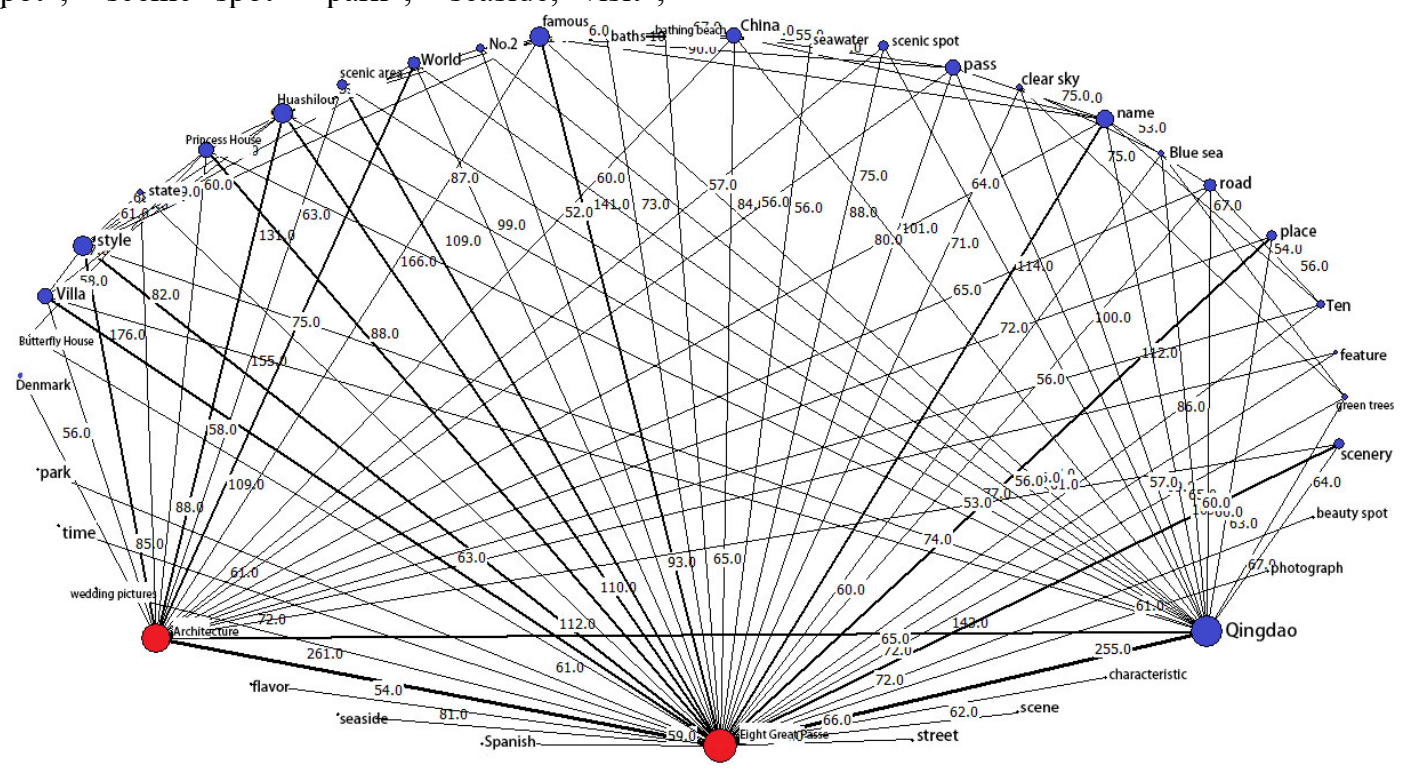

Figure 1 Semantic Network Diagram

As shown in Figure 1, through the centrality analysis, the coverage of figure is larger with the higher frequency and centrality of words, thus the centrality of "Qingdao", "architecture" and "Eight Great Passe" is very high. As the research subject, Eight Great Passe has the largest red coverage, undoubtedly the word with the highest centrality. And the architecture, is the only figure marked in red except for the Eight Great Passe with a high centrality, indicating that many of people's perceptions are directly related to architecture, which is consistent to the content above. The semantic network diagram further proves that the main perception of Eight Great Passe is architecture.

In addition, the values in the figure represent the co-occurrence word frequency. The higher the word frequency is, the higher the correlation degree is, and the thicker the lines are. It can be found that the words with high relevance to Eight Great Passe are "Qingdao", "architecture", "style", "villa", "name" and "Huashilou", which shows that tourists can fully comprehend the characteristics of Eight Great Passe. 


\subsection{Emotional Attitude Perception}

The number and percentage of positive, neutral and negative emotions can be obtained under the emotional analysis function of Rost content mining 6, which can clearly observe the emotional attitude of tourists towards Eight Great Passe of historical and Cultural District in Qingdao. In neutral and negative emotions, it's easier to find the existing problems of historical and cultural blocks.

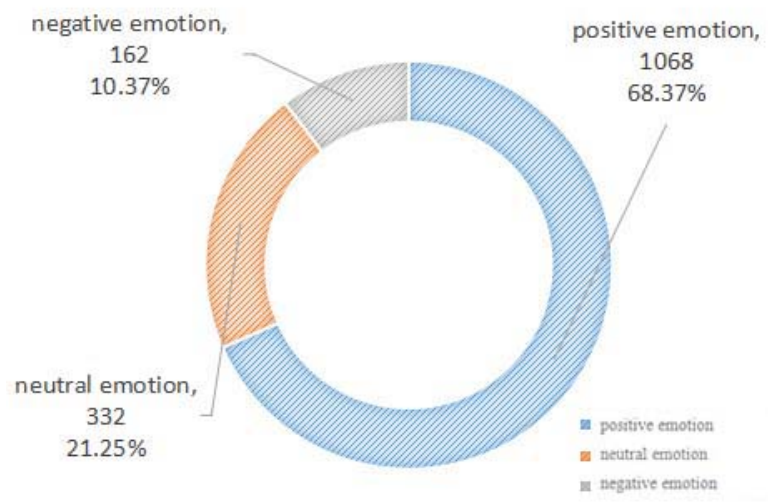

Figure 2 Percentage Chart of Emotional Attitude Perception

As shown in Figure 2, the frequency of positive emotion words of tourists to historical and cultural district of Eight Great Passe in Qingdao is 1068, accounting for $68.37 \%$ of the total with the largest proportion; the frequency of neutral emotional attitude words is 331 , accounting for $21.25 \%$ with a high proportion; the frequency of negative emotional attitude was 162 , accounting for $10.37 \%$ with the lowest proportion. It can be seen that tourists tend to hold positive emotional attitude perception to historical and cultural district of Eight Great Passe in Qingdao, while the proportion of neutral and negative emotional attitude perception cannot be ignored.

For example, a negative comment goes as this: Eight Great Passe is just a place for taking wedding photos or strolling. In addition to a variety of roads and chargeable former residences, there is really not funny here. I don't recommend it. The Marshal Building was not open to the public, and the next spot is Butterfly House, the ticket of which is 20 separately. I buy a package ticket of 40 yuan including the Butterfly House, Princess House and Spanish style pavilion. I don't think the Spanish style pavilion is worth visiting.

Among these negative emotions, we can find the problem in the tourists' perception about Eight Great Passe, which provides reference for the updating and improving for future combination of various opinions.

\section{Suggestions and Discussions}

It can be found that the tourist attractions are mainly concentrated in the coastal areas, distributing along the coastline. It's because that coastal resources are one of the most attractive tourism resources in Qingdao, and the development of tourist attractions along the coastline can give full play to the advantage ${ }^{5}$. And then it involves historical factors for most of these German style buildings built along the coast as military buildings during the German occupation have become tourist attractions now, making tourists be more attractive to this area. Facing the sea in the south, Eight Great Passe boasts its geographical advantage that enables it to develop better. The number of times Eight Great Passe appears in travel notes shows that it is a majority choice for tourists to Qingdao. However, in the travel notes, there are few descriptions of roads and buildings on the north side of it, and there are few descriptions of buildings which are not open to the public, which means that most tourists choose to walk on several roads near the seaside, and most tourists only pay attention to the buildings that have been opened. Without the detailed introduction of other buildings, they fail to enjoy the beauty of other roads and buildings, which can be a reference for future improvement.

People's cognition of Eight Great Passe historical block is mainly about sightseeing, their perception of tourist attractions is high, while the perception towards life service such as catering, coffee shop, accommodation is low. There are no relevant words in the top 50 high-frequency words, and are rarely recorded in travel notes. Through on-the-spot investigation, some facilities and signboards of storefront are lack of cultural connotation, and even some stores have destroyed the overall appearance of the block.

As for tourist's attitude, many people don't consider Eight Great Passe funny. According to the high-frequency words, the $2^{\text {nd }}$ Bathing Beach ranks 14th, a relatively high position. Then comes the activities about visiting and walking. The architecture should be the most distinctive part in Eight Great Passe, the activities related to architecture should be the main activities in the block. It shows that people just only pay a sightseeing to it without more feeling of participation or experience. The participation of the people is related to the space, the type and quality of activities. In order to enhance the participation, it is necessary to create attractive, participatory and experiential spaces and activities to attract people, making people feel interesting, historical and fun. This also needs to be concerned and improved.

There are also some deficiencies in this study. Firstly, it calls for more sample data in the next research for the data is not sufficient enough in this paper; secondly, the author mainly focuses on the text content by analyzing word frequency with software without more study on the pictures and videos created by tourists. They are two pointcuts in the follow-up research.

\section{References}

1. Xiao Yang, Xie Shuangyu, Wang Xiaofang. Analysis of tourists' perception of historical and cultural blocks in Wuhan Based on online travel notes [J]. Tourism research, 2017, 9 (01): 83-94.

2. Yao Tiantian, Fang Xuhong. A study on the effect of tourism development in historical districts based on Internet text -- a case study of wudian city in 
Jinjiang City [J]. Tourism research, 2017,9 (04): 39-49.

3. Chen Bingjie, Hu Wei. Research on tourist perception of historical blocks based on Text Mining: a case study of Pingjiang road in Suzhou [J]. Journal of Yunnan Agricultural University (SOCIAL SCIENCE), 2016,10 (04): 48-55.

4. Ma Yue. A new method of public Poe based on network information analysis [J]. New building, 2017 (06): 62-65.

5. Chai Shousheng, Zhu Fujun. Image perception of Qingdao tourism destination based on Weblog [J]. Journal of China University of Petroleum (SOCIAL SCIENCE EDITION), 2018,34 (04): 24-31. 